Supplementary Information

\title{
Polymorph-Derived Diversification of Crystal Actuation by Photoisomerization and the Photothermal Effect
}

Shodai Hasebe, ${ }^{\dagger}$ Yuki Hagiwara, ${ }^{\dagger}$ Kyoko Takechi,, Tetsuro Katayama, ${ }^{\ddagger}$ Akihiro Furube,‡Toru Asahi,, § Hideko Koshima* $§$

'Department of Advanced Science and Engineering, Graduate School of Advanced Science and Engineering, Waseda University, Tokyo 169-8555, Japan

\#Department of Materials Science and Biotechnology, Graduate School of Science and Engineering, Ehime University, Matsuyama 790-8577, Japan

*Department of Optical Science, Tokushima University, Tokushima 770-8506, Japan

${ }^{\S}$ Research Organization for Nano and Life Innovation, Waseda University, Tokyo 162- 0041, Japan

* Correspondence to h.koshima@kurenai.waseda.jp 


\section{CONTENTS}

1. Thermal analysis

Figure S1 3

2. Crystal structures

Table S1, Figures S2-S4 4

3. Spectroscopy

Figures S5-S8 8

4. Bending of the $1 \alpha$ crystal by photoisomerization

Figures S9-11 12

5. Bending of the $1 \beta$ crystal by the photothermal effect

Figures S12-S17 15

6. Two-step bending of the thick $1 \alpha$ crystal by the combination of photoisomerization and the photothermal effect

$\begin{array}{ll}\text { Figures S18-S20 } & 21\end{array}$

7. Bending of the $1 \beta$ polycrystal by the photothermal effect

$\begin{array}{ll}\text { Figure S21 } & 24\end{array}$

8. Experimental section 25

9. List of movies

Movies S1-S5 26

10. References 


\section{Thermal analyses}

a

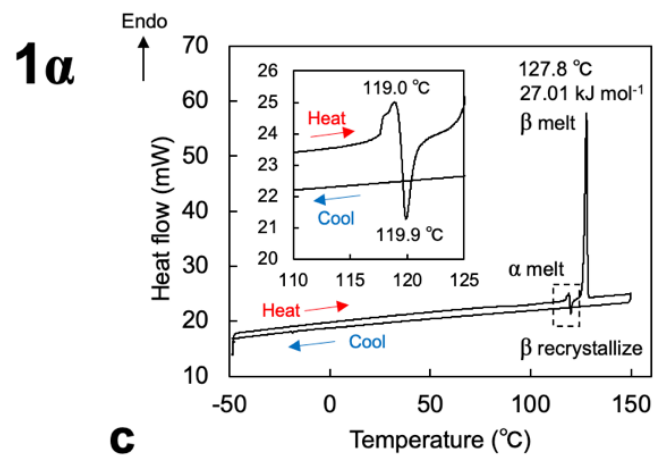

b

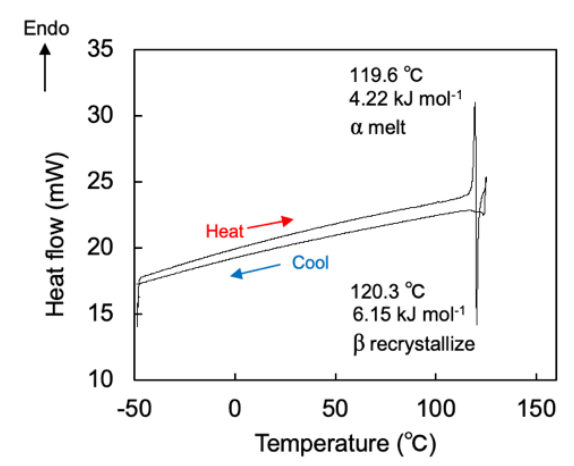

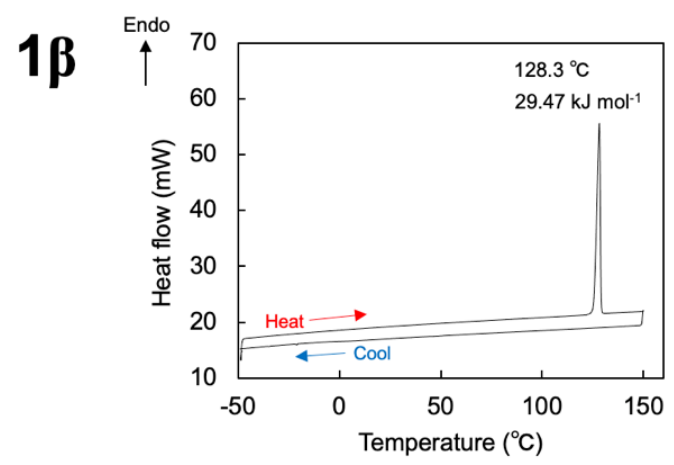

Figure S1 Differential scanning calorimetry (DSC) curves of the (a, b) $\mathbf{1} \alpha$ and (c) $\mathbf{1 \beta}$ crystals measured in the temperature range from $(\mathrm{a}, \mathrm{c})-50$ to $150^{\circ} \mathrm{C}$ and $(\mathrm{b})-50$ to $125^{\circ} \mathrm{C}$ upon heating and then cooling.

Differential scanning calorimetry (DSC) measurements were performed using a differential scanning calorimeter (DSC 8500, Perkin Elmer, Waltham, MA, USA) at a speed of $5^{\circ} \mathrm{C} \mathrm{min}^{-1}$ for heating and cooling under $\mathrm{N}_{2}$ gas at atmospheric pressure. 


\section{Crystal structures}

Table S1. Crystallographic constants of the enol-1 $\alpha$ and enol-1 $\beta$ crystals.

\begin{tabular}{|c|c|c|}
\hline & enol-1a & enol-1及 \\
\hline Temperature $\left({ }^{\circ} \mathrm{C}\right)$ & 20 & 20 \\
\hline Crystal system & Triclinic & Monoclinic \\
\hline Space group & $P \overline{1}$ & $P n a 2_{1}$ \\
\hline$a(\AA)$ & $6.517(4)$ & $12.436(2)$ \\
\hline$b(\AA)$ & $10.585(8)$ & $9.0649(15)$ \\
\hline$c(\AA)$ & $14.634(12)$ & $16.753(3)$ \\
\hline$\alpha\left(^{\circ}\right)$ & $80.28(3)$ & 90 \\
\hline$\beta\left(^{\circ}\right)$ & $81.87(3)$ & 90 \\
\hline$\gamma\left({ }^{\circ}\right)$ & $75.30(3)$ & 90 \\
\hline$V\left(\AA^{3}\right)$ & $957.3(13)$ & $1888.6(5)$ \\
\hline$Z$ & 2 & 4 \\
\hline$\rho_{\text {calc }}\left(\mathrm{g} \mathrm{cm}^{-3}\right)$ & 1.136 & 1.152 \\
\hline$R_{I}[I>2 \sigma(I)]$ & 0.0536 & 0.0384 \\
\hline$w R_{2}[I>2 \sigma(I)]$ & 0.1698 & 0.0931 \\
\hline GOF & 1.071 & 1.169 \\
\hline
\end{tabular}



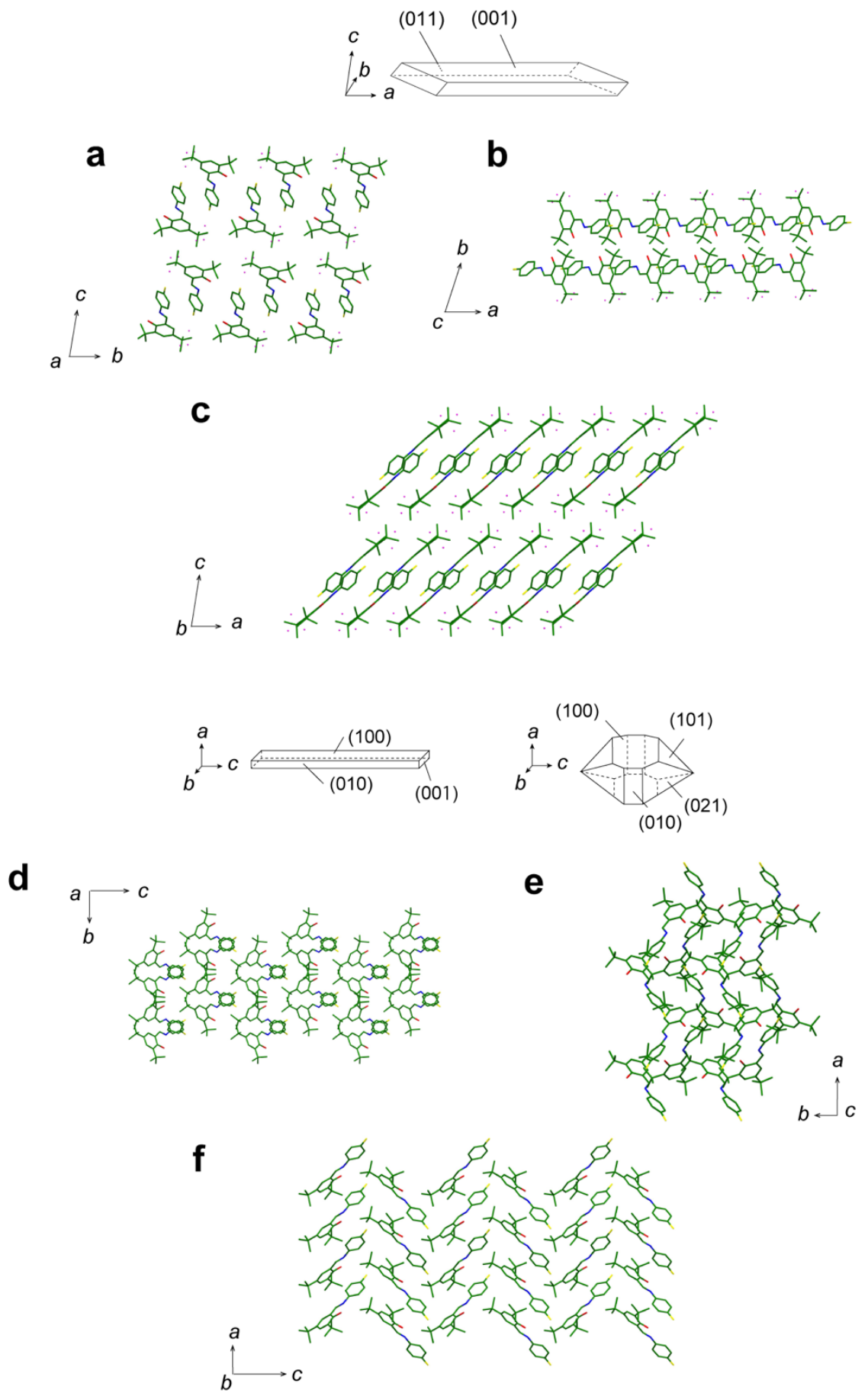

Figure S2. Packing diagrams on the (a, d) (100), (b, e) (001), (c) (010), and (f) (010) faces for (a-c) $1 \alpha$ and ( $d-f) \mathbf{1} \beta$ crystals. Hydrogen atoms are omitted for clarify. 
a

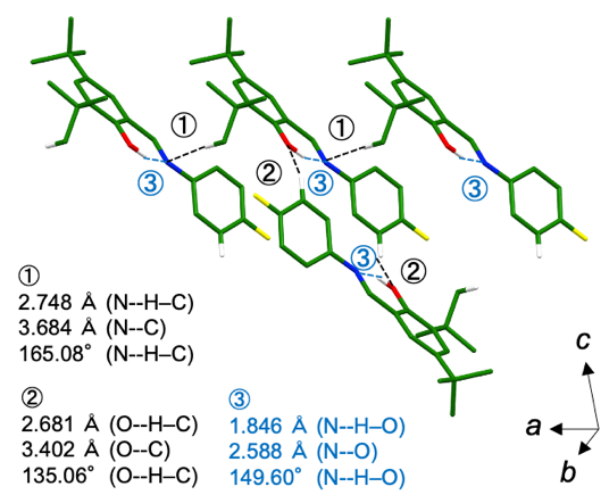

b

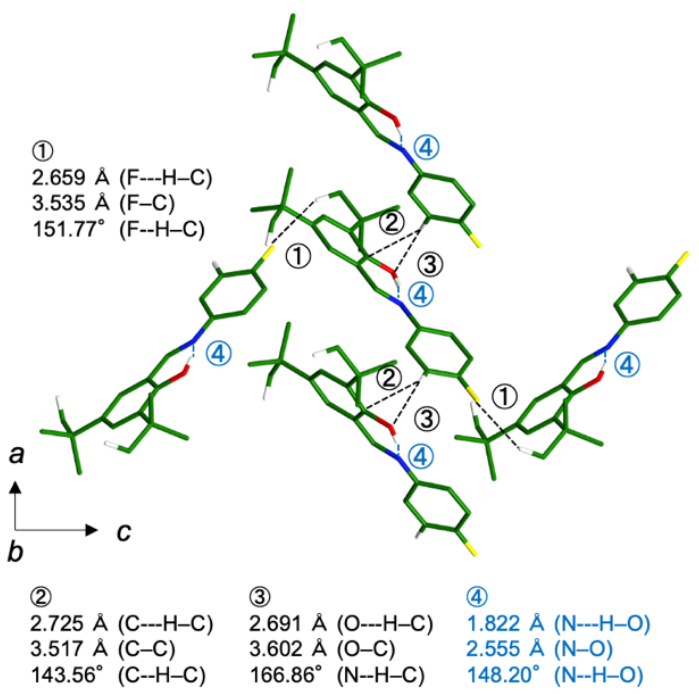

Figure S3. Short contacts of the (a) $1 \alpha$ and (b) $1 \boldsymbol{\beta}$ crystals. Intermolecular and intramolecular interactions are represented as black and blue lines, respectively. Disordered structures in the $\mathbf{1 \alpha}$ crystal and some hydrogens are omitted for clarify. 

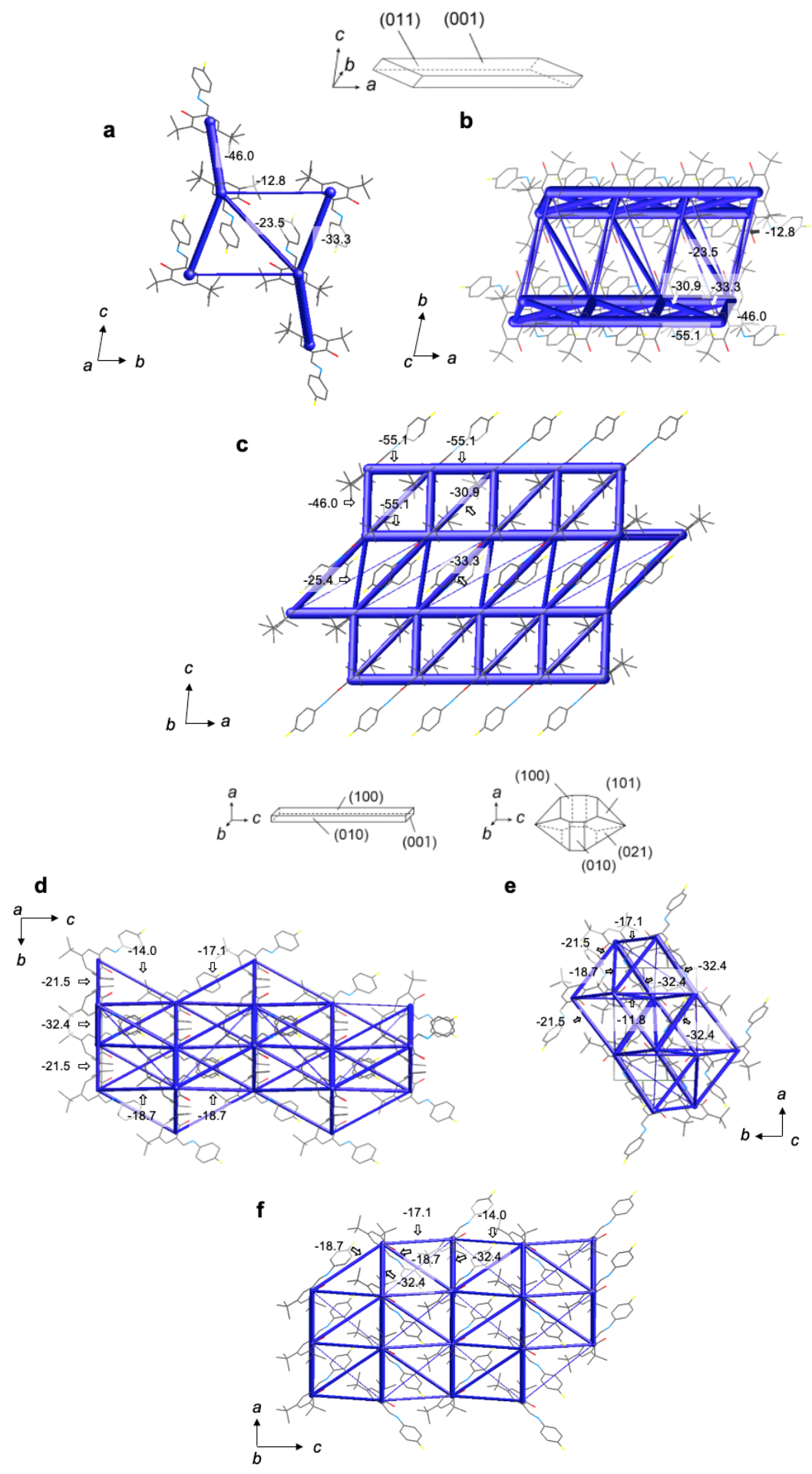

Figure S4. Energy frameworks showing the total interaction energies on the (a, d) (100), (b, e) (001), (c) $(0 \overline{1} 0)$, and (f) (010) faces for $(a-c) \mathbf{1} \alpha$ and $(d-f) \mathbf{1 \beta}$ crystals calculated with CrystalExplorer. ${ }^{1}$ Disordered structures and hydrogen atoms are omitted for clarify. The numbers indicate interaction energies $\left(\mathrm{kJ} \mathrm{mol}^{-1}\right)$. 


\section{Spectroscopy}

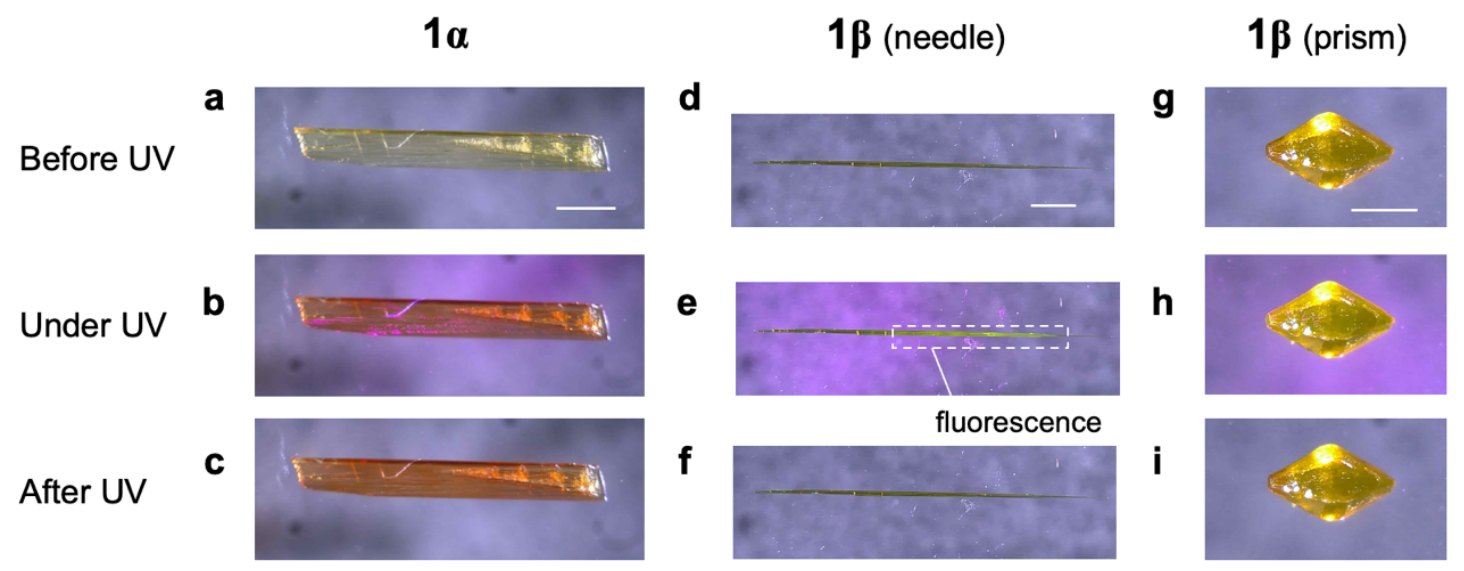

Figure S5. Photos of $(\mathrm{a}-\mathrm{c})$ a plate-like $1 \alpha,(\mathrm{d}-\mathrm{f})$ a needle-like $\mathbf{1 \beta}$, and $(\mathrm{g}-\mathrm{i})$ a prism-like $\mathbf{1 \beta}$ crystals (a, $\mathrm{d}, \mathrm{g}$ ) before, $(\mathrm{b}, \mathrm{e}, \mathrm{h})$ under, and (c, f, i) after UV-LED irradiation for $30 \mathrm{~s}$. The $\mathbf{1} \boldsymbol{\alpha}$ crystal exhibited a color change from pale-yellow to red whereas the $\mathbf{1 \beta}$ crystals kept its original yellow color; instead, the $1 \beta$ crystals emitted yellow fluorescence (Figure S7). Scale bars, $500 \mu \mathrm{m}$. 

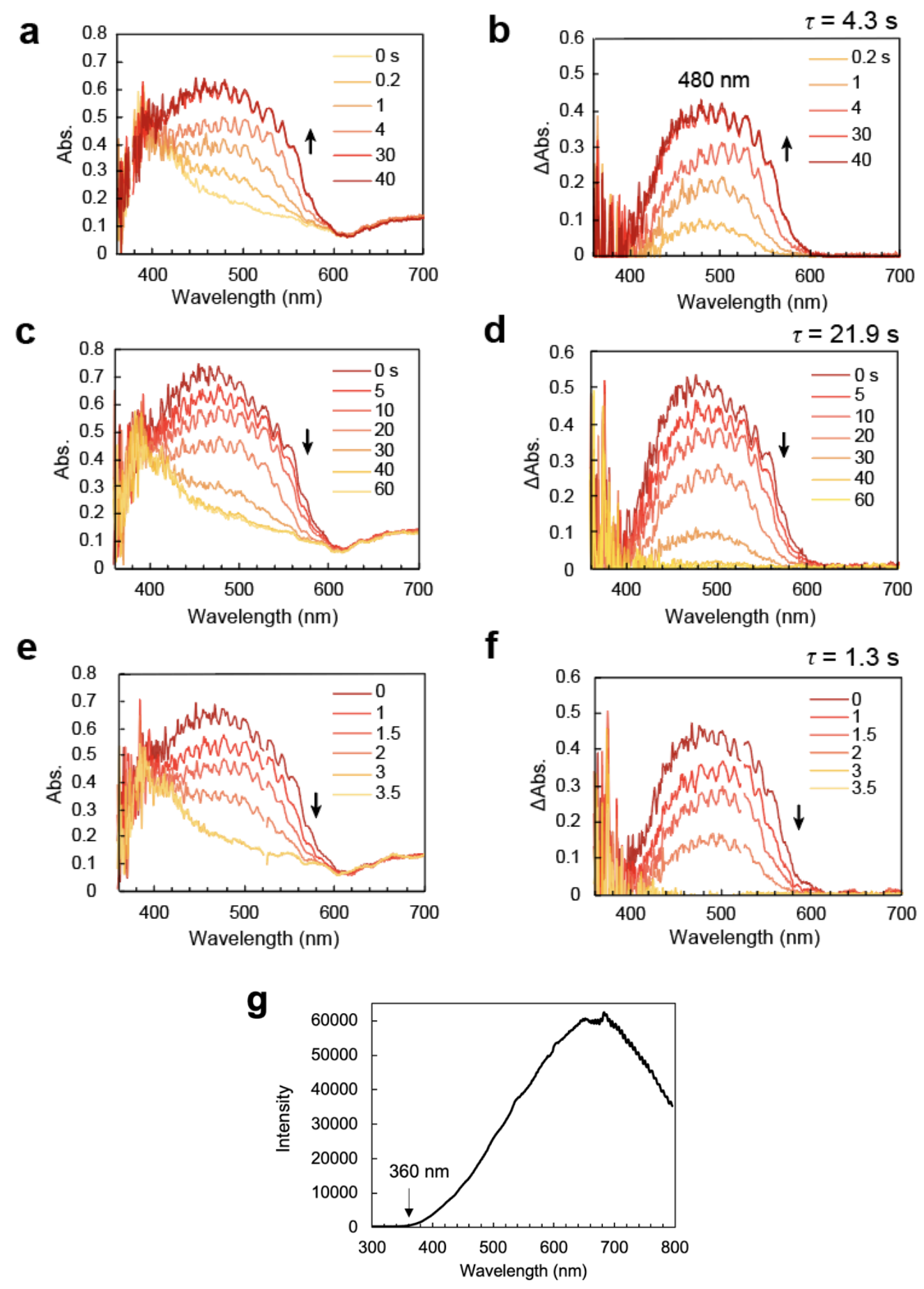

Figure S6. (a, c, e) UV-visible (UV-vis) absorption spectra and (b, d, f) difference spectra of a single thin plate-like $1 \alpha$ crystal on the (001) face before and after UV light ( $375 \mathrm{~nm}, 90 \mathrm{~mW} \mathrm{~cm}{ }^{-2}$ ) irradiation at room temperature. (a, b) UV light irradiation, (c, d) thermal back after UV light irradiation for $60 \mathrm{~s}$, (e, f) visible light $\left(520 \mathrm{~nm}, 62 \mathrm{~mW} \mathrm{~cm}^{-2}\right.$ ) irradiation after UV light irradiation for $60 \mathrm{~s}$. (g) Intensity of the measurement light (a $68 \mathrm{~W}$ xenon lamp). 


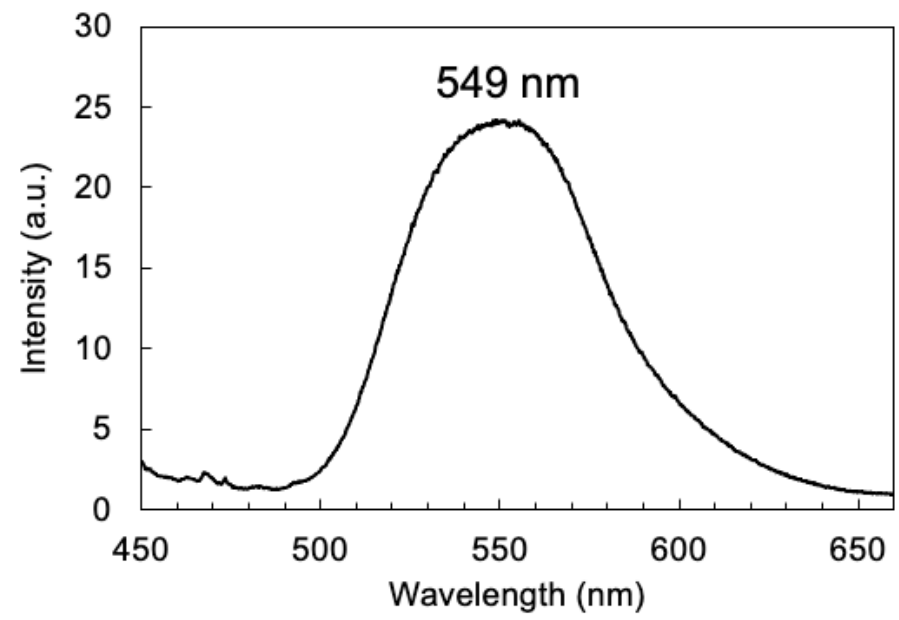

Figure S7. A steady-state fluorescence spectrum of the powder enol-1ß crystals upon UV (365 nm) excitation with a maximum wavelength at $549 \mathrm{~nm}$. 


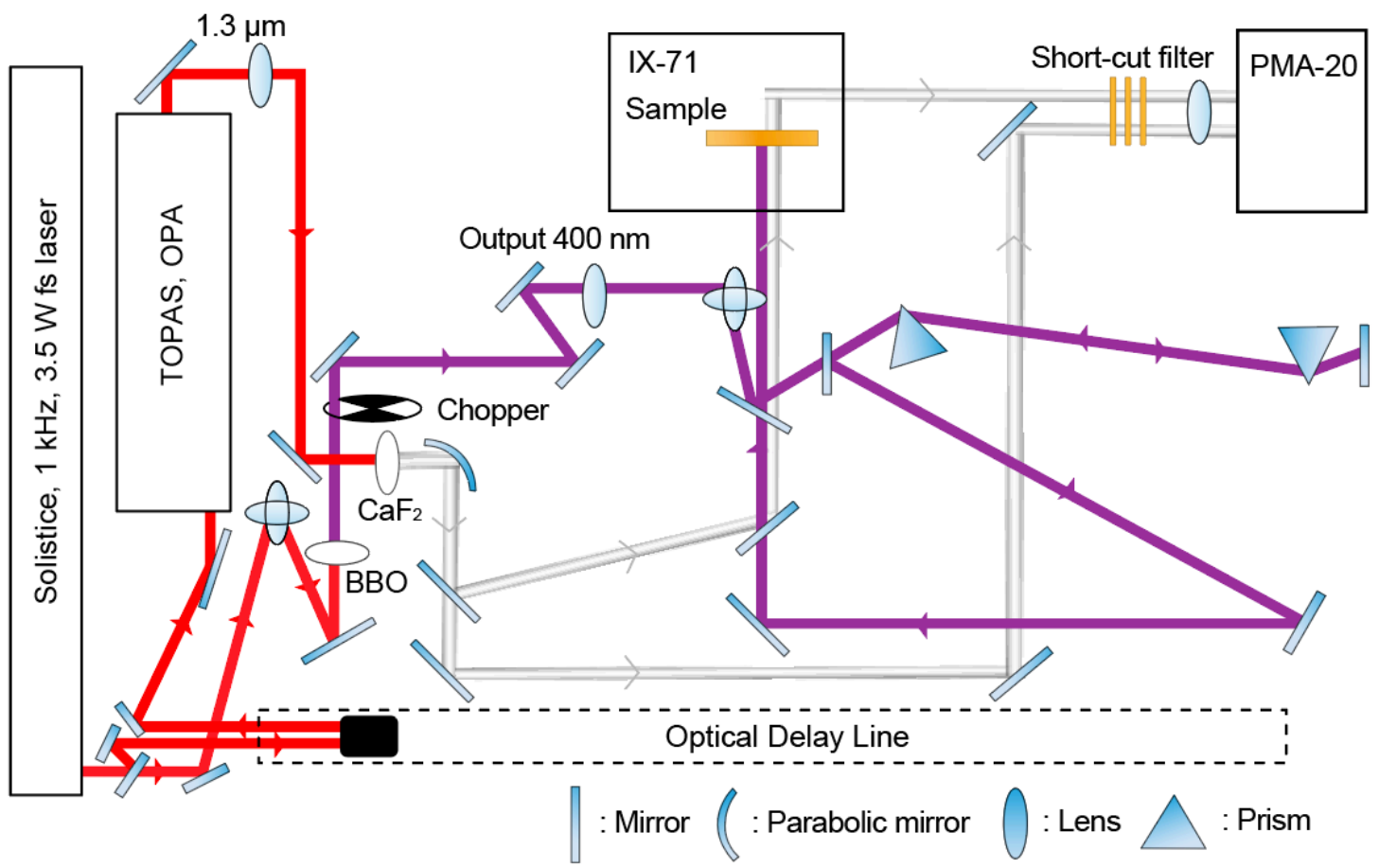

Figure S8. Experimental setup for femtosecond transient absorption spectra. 


\section{Bending of the $1 \alpha$ crystal by photoisomerization}

a

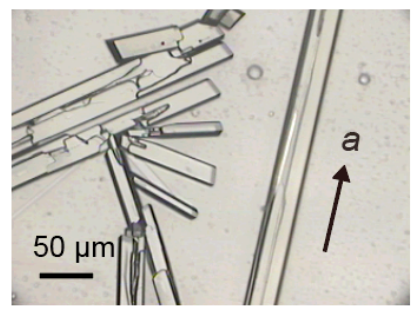

C

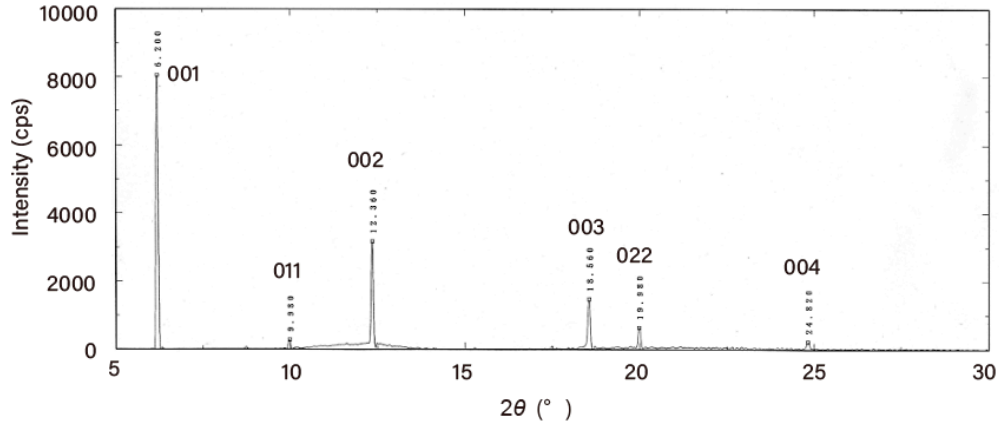

d

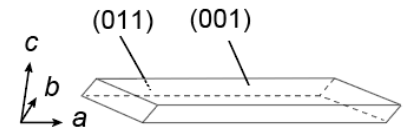

b

\begin{tabular}{cll}
\hline Face indices & $2 \theta / /^{\circ}$ & $d$ value $/ \AA$ \\
\hline 001 & 6.20 & 14.25 \\
011 & 9.98 & 8.86 \\
002 & 12.36 & 7.16 \\
003 & 18.56 & 4.78 \\
022 & 19.98 & 4.44 \\
004 & 24.82 & 3.59 \\
\hline
\end{tabular}

Figure S9. (a) A photograph of plate-like microcrystals of $1 \alpha$ prepared by sublimation on a silanated glass plate. (b) List of face indices, $2 \theta$, and $d$ value for each peak in part c. (c) X-ray diffraction profile of $1 \alpha$ microcrystals $(\lambda=1.54187 \AA)$. (d) Face indexing of the plate-like $1 \alpha$ crystal. 

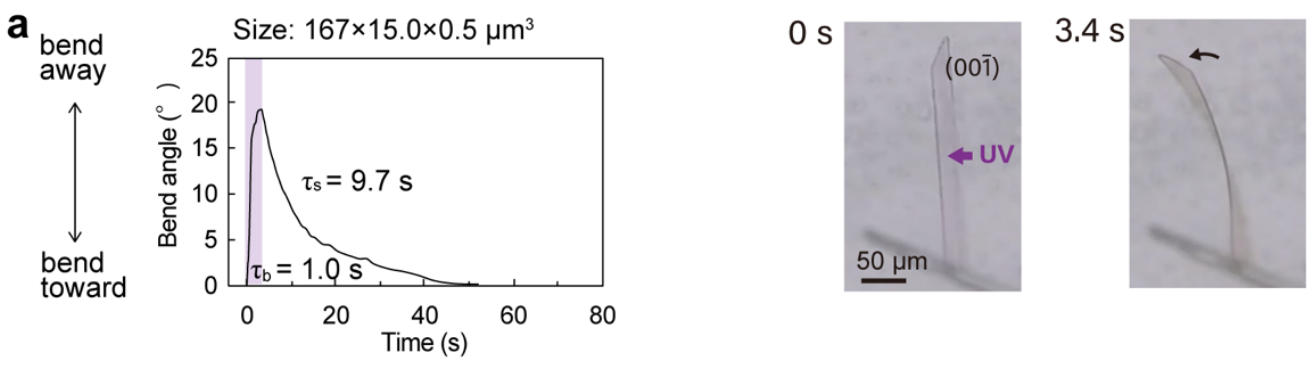

b

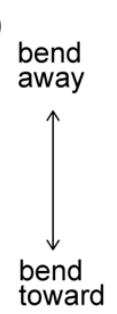

Size: $2460 \times 121 \times 12.6 \mu \mathrm{m}^{3}$
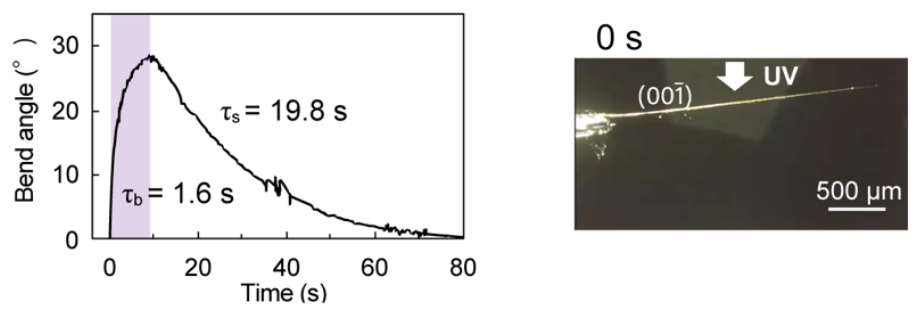

$10 \mathrm{~s}$
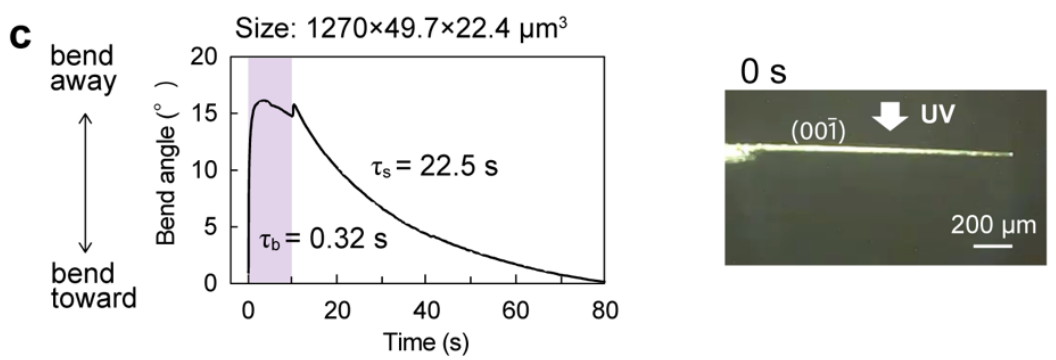

$10 \mathrm{~s}$

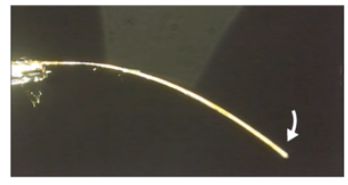

d

Size: $2920 \times 451 \times 136 \mu \mathrm{m}^{3}$
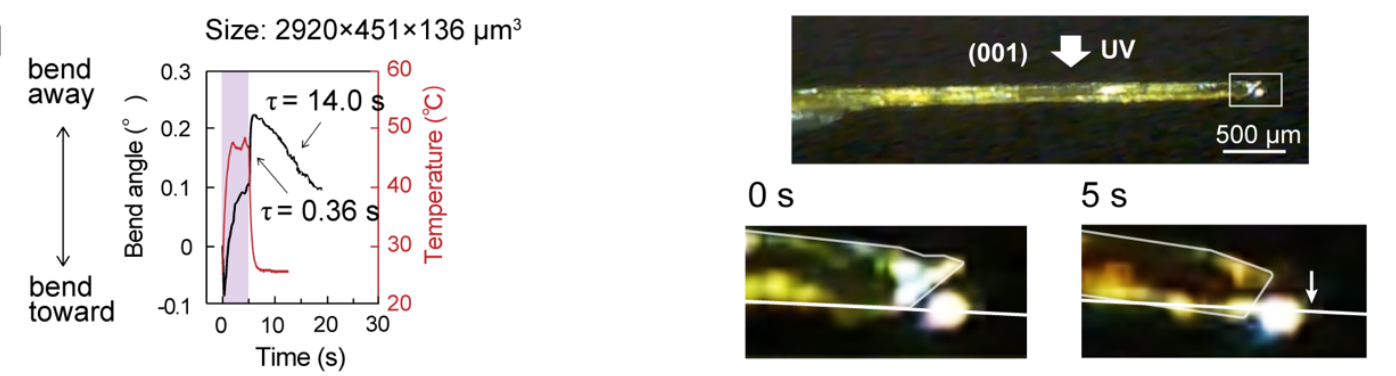

Figure S10. Bending of $\mathbf{1} \alpha$ crystals with different thickness upon UV-LED (365 nm, (a) 180, (b-d) $1300 \mathrm{~mW} \mathrm{~cm}^{-2}$ ) irradiation. Note that thick crystals (c, d) bend not only by photoisomerization but also by the photothermal effect. 


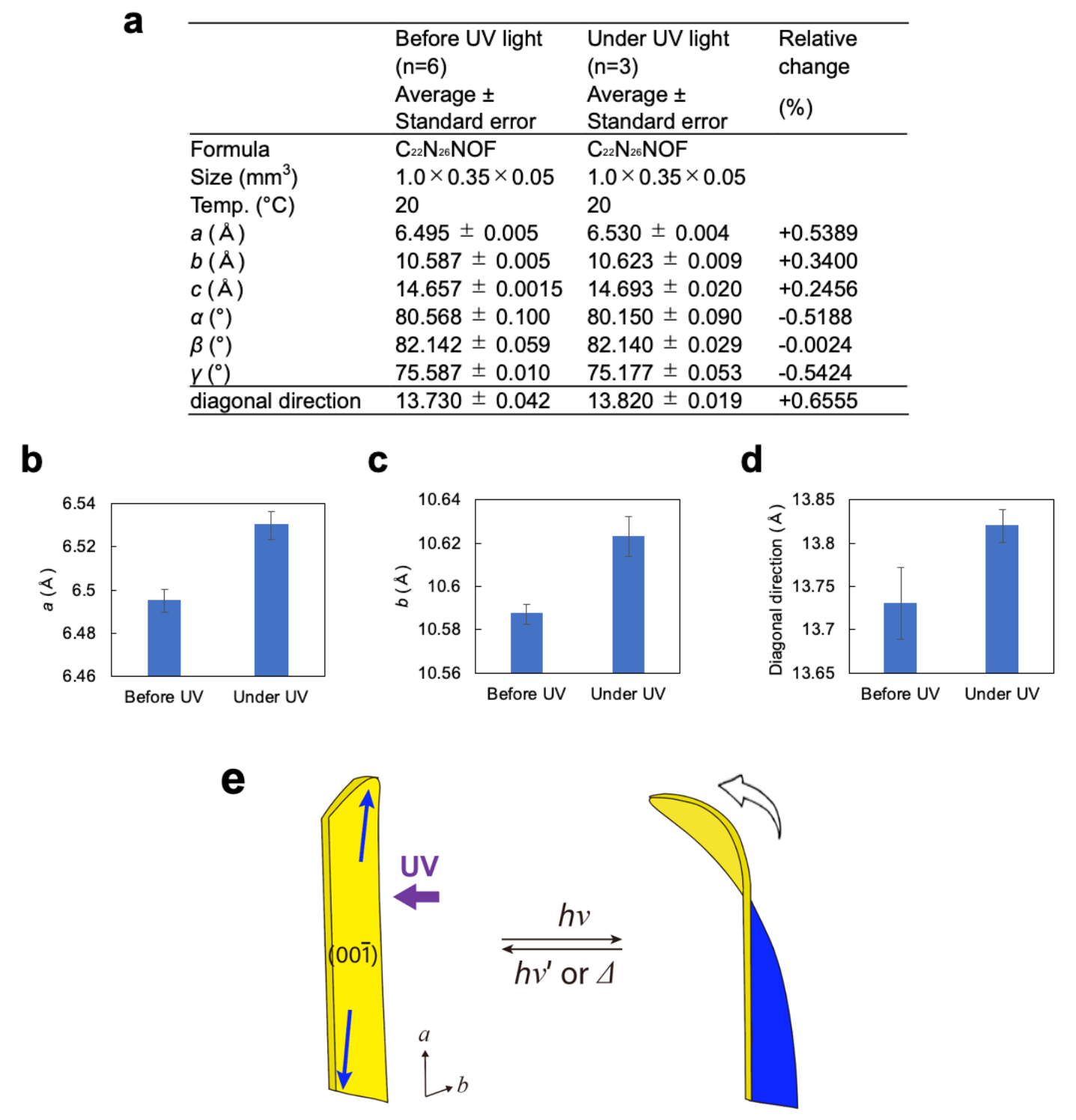

Figure S11. (a) Unit cell parameters changes of a $1 \alpha$ crystal and (b-d) statistical evaluation of the changes of (b) $a$-axis, (c) $b$-axis, and (d) diagonal direction of the (001) plane before (n=6) and under $(\mathrm{n}=3) \mathrm{UV}$ laser $\left(375 \mathrm{~nm}, 960 \mathrm{~mW} \mathrm{~cm}{ }^{-2}\right)$ exposure at $20^{\circ} \mathrm{C}$. (e) Schematic illustration of bending mechanism with a twist of the $1 \alpha$ crystal. 


\section{Bending of the $1 \beta$ crystal by the photothermal effect}

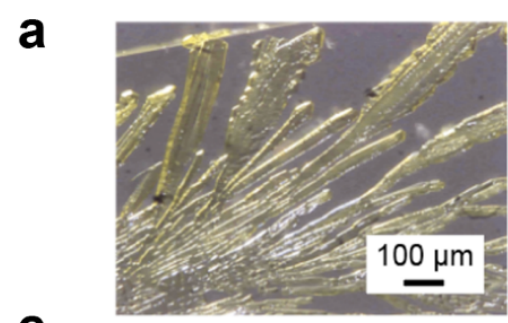

b

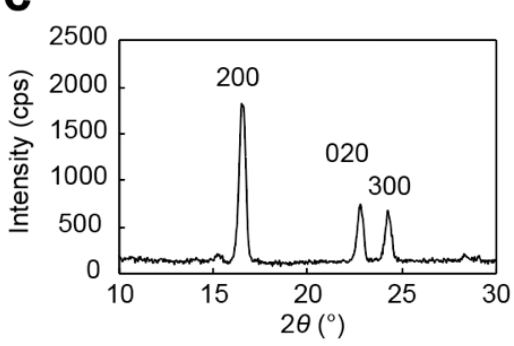

\begin{tabular}{ccc}
\hline Face indices & $2 \theta /^{\circ}$ & $d$ value $/ \AA$ \\
\hline 200 & 16.56 & 6.21 \\
020 & 22.84 & 4.52 \\
300 & 24.28 & 4.25 \\
\hline
\end{tabular}

d

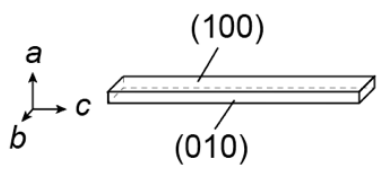

Figure S12. (a) A photograph of needle-like microcrystals of $1 \beta$ prepared by sublimation on a glass plate. (b) List of face indices, $2 \theta$, and $d$ value for each peak in part c. (c) X-ray diffraction profiles of $\mathbf{1 \beta}$ microcrystals $(\lambda=1.78892 \AA)$. (d) Face indexing of the needle-like $\mathbf{1 \beta}$ crystal. 
a

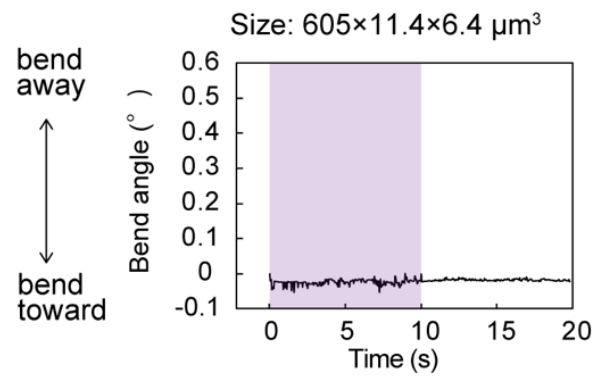

b

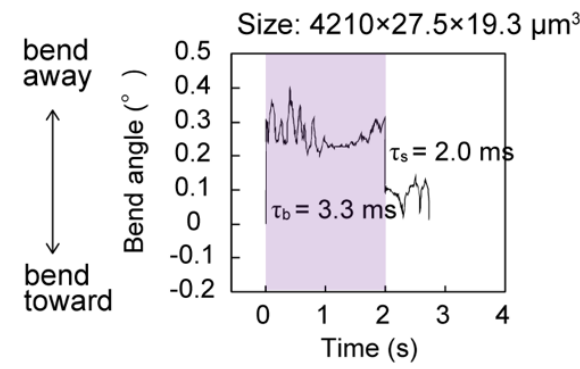

C

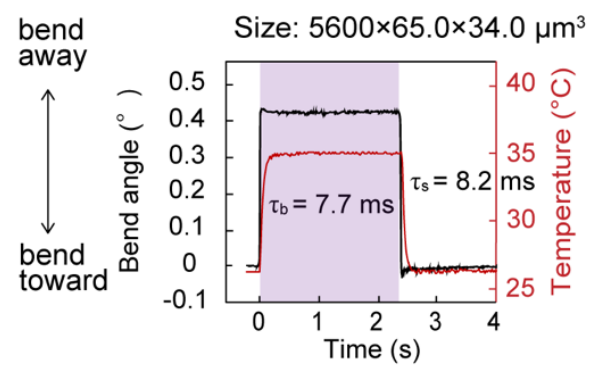

d

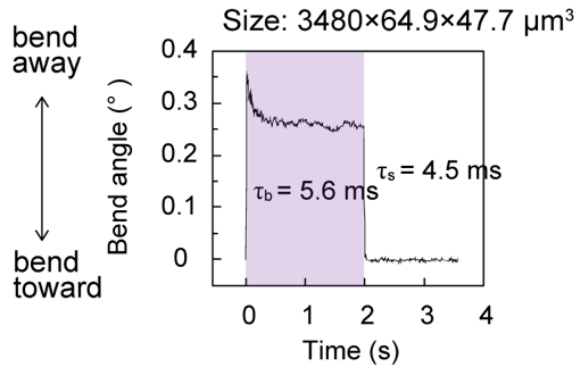

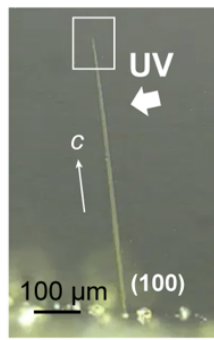
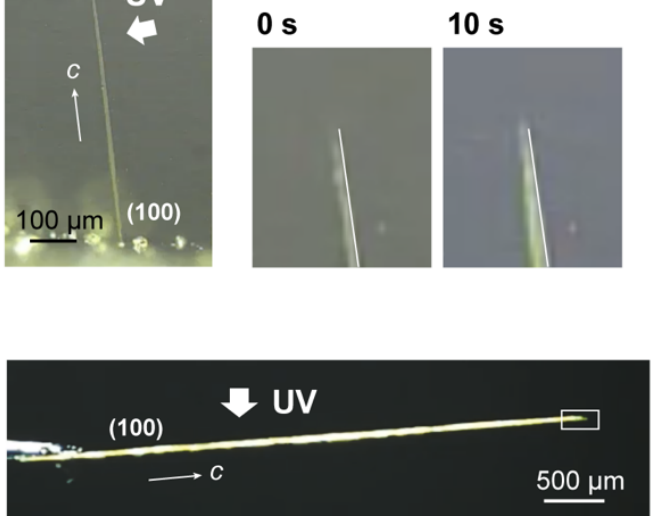

$0 \mathrm{~s}$

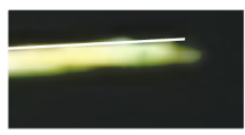

$2 \mathrm{~s}$
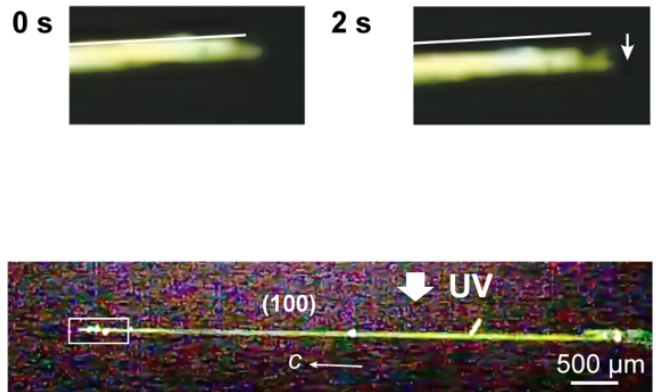

os

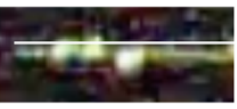

$2.4 \mathrm{~s}$
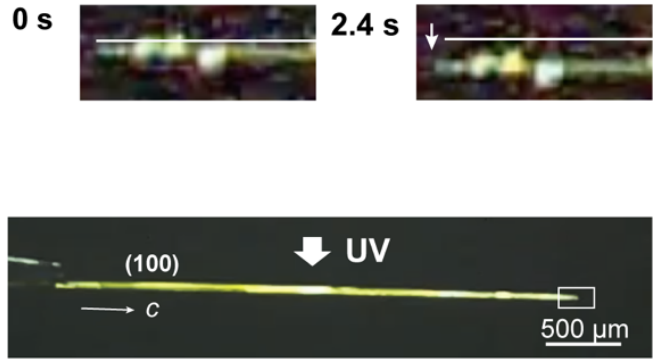

$0 \mathrm{~s}$

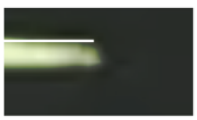

$2 \mathrm{~s}$

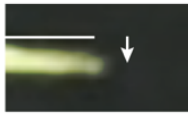

Figure S13. Bending of needle-like 1及 crystals with different thickness (a) upon UV-LED (365 nm, $1300 \mathrm{~mW} \mathrm{~cm}^{-2}$ ) or (b-d) upon UV laser (375 nm, $\left.960 \mathrm{~mW} \mathrm{~cm}^{-2}\right)$ irradiation. 
a

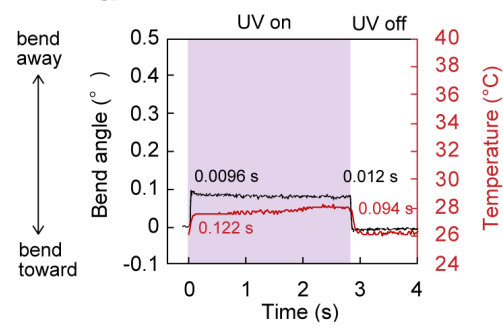

d

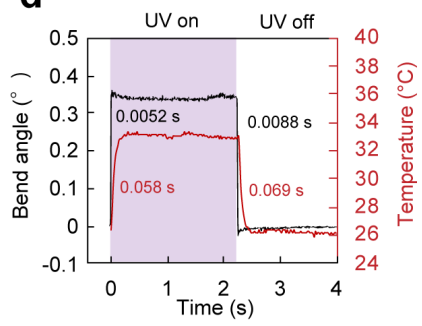

b

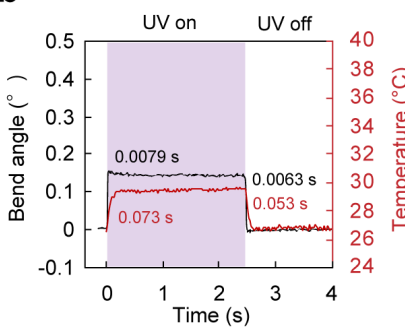

e

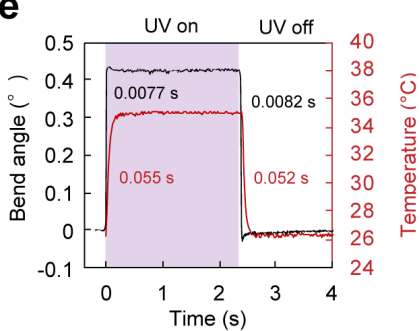

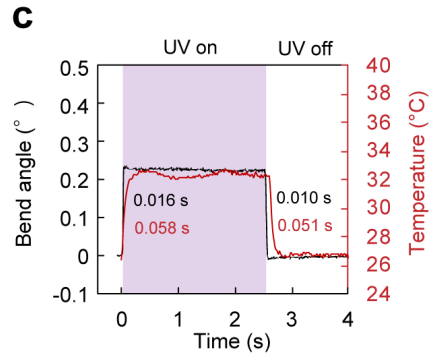

\section{f}

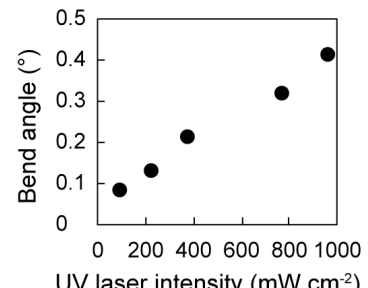

$\mathbf{h}$

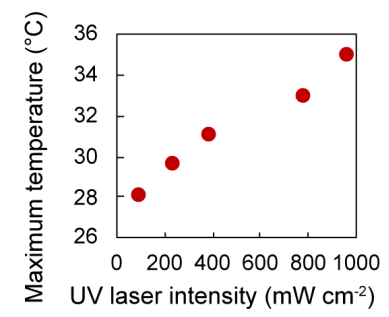

g

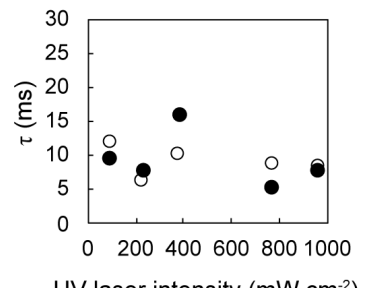

i

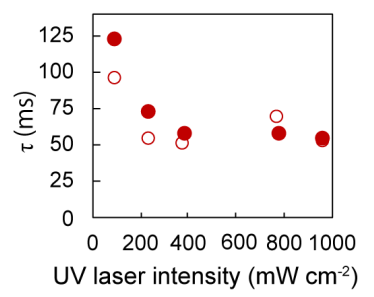

Figure S14. (a-e) Time dependence of the bend angle (black line) and top surface temperature (red line) of a large needle-like $1 \beta$ crystal $\left(5600 \times 65.0 \times 34.0 \mu \mathrm{m}^{3}\right)$ by UV laser with an intensity of (a) 90 , (b) 230 , (c) 380 , (d) 770 , and (e) $960 \mathrm{~mW} \mathrm{~cm}^{-2}$. The numbers in the graphs indicate time constants. ( $\mathrm{f}-\mathrm{i}$ ) UV laser intensity dependence of (f) the maximum bend angle, $(\mathrm{g})$ time constants for bending (black solid circles) and for straightening (black open circles), (h) maximum temperature, and (i) time constants for time constants for temperature increase (red solid circles) and decrease (red open circles). 
a

\begin{tabular}{llll}
\hline & $\begin{array}{l}20{ }^{\circ} \mathrm{C} \\
(\mathrm{n}=5)\end{array}$ & $\begin{array}{l}40{ }^{\circ} \mathrm{C} \\
(\mathrm{n}=5)\end{array}$ & $\begin{array}{l}60{ }^{\circ} \mathrm{C} \\
(\mathrm{n}=5)\end{array}$ \\
& $\begin{array}{l}\text { Average } \pm \\
\text { Standard error }\end{array}$ & $\begin{array}{l}\text { Average } \pm \\
\text { Standard error }\end{array}$ & $\begin{array}{l}\text { Average } \pm \\
\text { Standard error }\end{array}$ \\
\hline Formula & $\mathrm{C}_{22} \mathrm{~N}_{26} \mathrm{NOF}$ & $\mathrm{C}_{22} \mathrm{~N}_{26} \mathrm{NOF}$ & $\mathrm{C}_{22} \mathrm{~N}_{26} \mathrm{NOF}$ \\
Size $\left(\mathrm{mm}^{3}\right)$ & $0.55 \times 0.50 \times 0.45$ & $0.55 \times 0.50 \times 0.45$ & $0.55 \times 0.50 \times 0.45$ \\
$a(\AA)$ & $12.4364 \pm 0.0015$ & $12.4504 \pm 0.0038$ & $12.4668 \pm 0.0010$ \\
$b(\AA)$ & $9.0612 \pm 0.0027$ & $9.0758 \pm 0.0010$ & $9.0946 \pm 0.0012$ \\
$c(\AA)$ & $16.7416 \pm 0.0011$ & $16.7756 \pm 0.0033$ & $16.799 \pm 0.0020$ \\
$\alpha\left({ }^{\circ}\right)$ & $90.0125 \pm 0.0226$ & $90.01 \pm 0.0543$ & $89.99 \pm 0.0246$ \\
$\beta\left({ }^{\circ}\right)$ & $90.0575 \pm 0.0085$ & $89.96 \pm 0.0031$ & $90.04 \pm 0.0105$ \\
$y\left({ }^{\circ}\right)$ & $90.02 \pm 0.0063$ & $89.87 \pm 0.2083$ & $90.01 \pm 0.0063$ \\
\hline
\end{tabular}
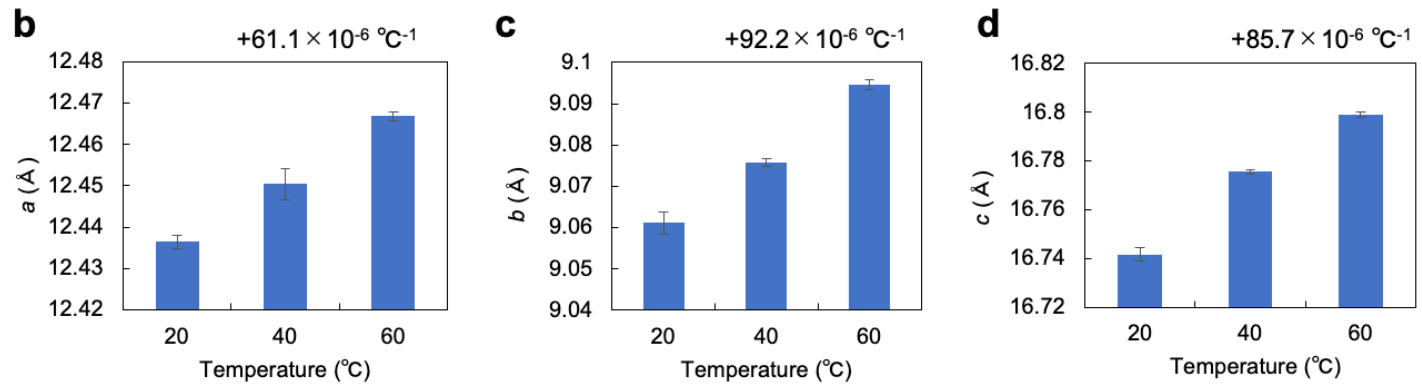

e

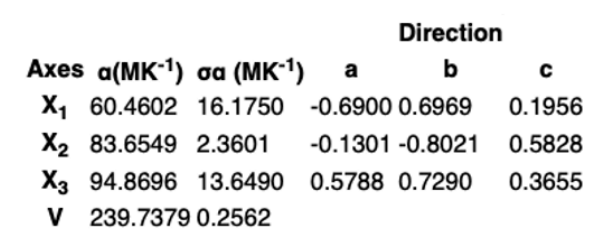

$\mathbf{f}$

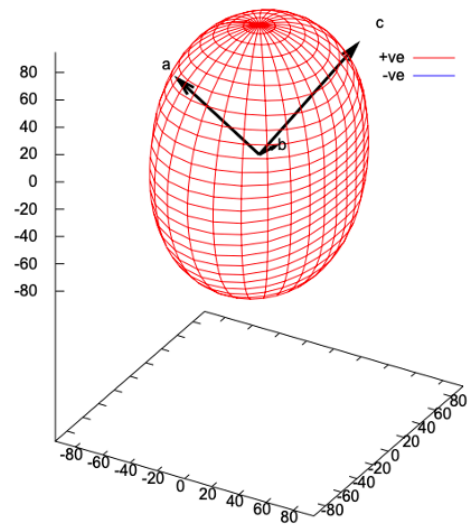

Figure S15. (a) Unit cell parameters of a $1 \beta$ crystal at 20,40 , and $60^{\circ} \mathrm{C}$. (b-d) Change in length of (b) $a$-, (c) $b$-, and (d) $c$-axes. The numbers in the upper right corner of the graphs indicate the coefficient of thermal expansion. (e) The principal components of the expansivity tensor. $\boldsymbol{a}$ represents the coefficient of thermal expansion $\left(\times 10^{-6}\right)$. (f) The expansivity indicatrix for $\mathbf{1} \boldsymbol{\beta}$ calculated by using the software, PASCal, ${ }^{2}$ indicating that upon heating the $\mathbf{1 \beta}$ crystal expands to all directions with a thermal expansion coefficient around $60-90 \times 10^{-6}{ }^{\circ} \mathrm{C}^{-1}$. 

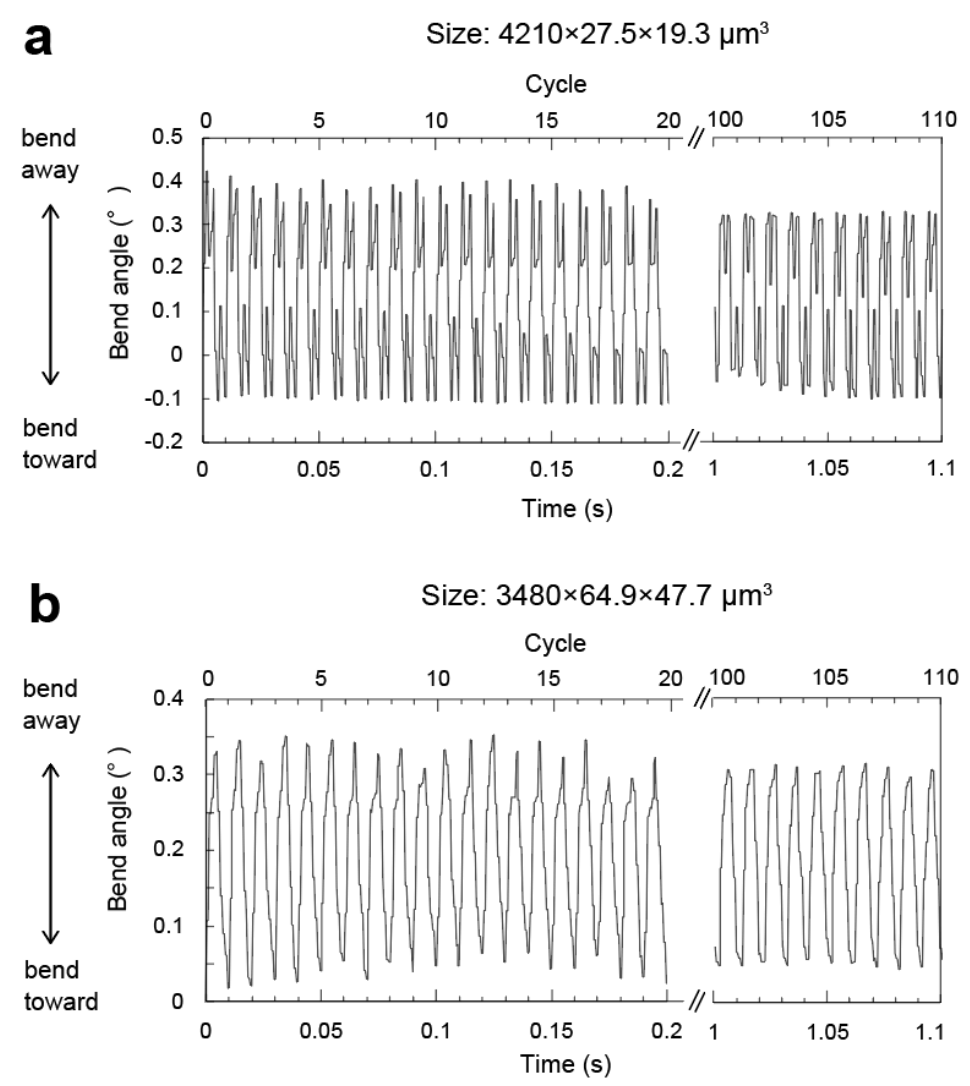

Figure S16. High-frequency $(100 \mathrm{~Hz}$ ) bending of needle-like $\mathbf{1} \boldsymbol{\beta}$ crystals by pulsed irradiation $(5 \mathrm{~ms}$ on $/ 5 \mathrm{~ms}$ off) of the UV laser $\left(960 \mathrm{~mW} \mathrm{~cm}^{-2}\right.$ ). Crystal size: (a) $4210 \times 27.5 \times 19.3 \mu^{3}$ (b in Figure S13), (b) $3480 \times 64.9 \times 47.7 \mu \mathrm{m}^{3}(\mathrm{~d}$ in Figure S13) 

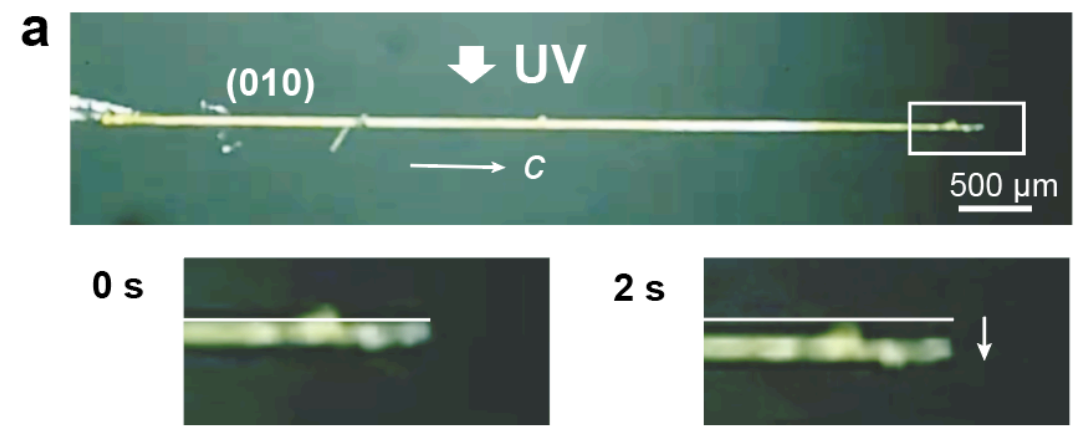

b

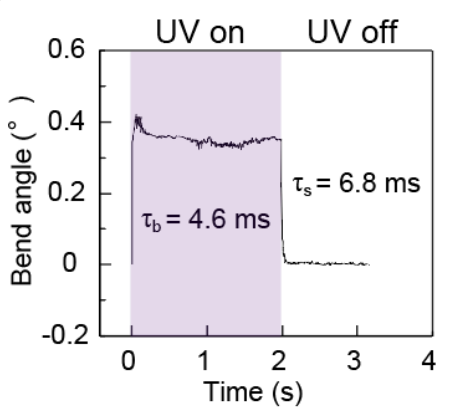

C

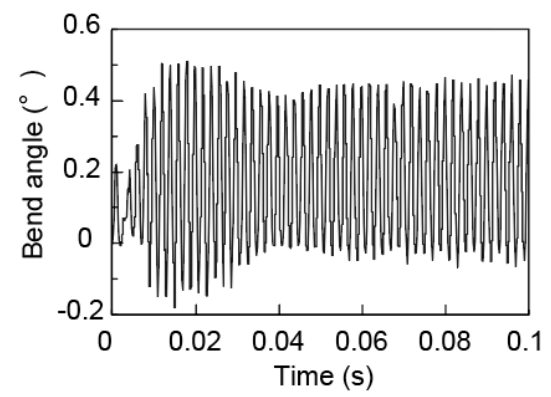

Figure S17. Bending of a large needle-like $\mathbf{1 \beta}$ crystal $\left(5600 \times 65.0 \times 34.0 \mu \mathrm{m}^{3}\right.$, the same crystal in Figure 6 and Figure S13c) by the photothermal effect upon UV laser $\left(960 \mathrm{~mW} \mathrm{~cm}^{-2}\right)$ irradiation on the (010) face. (a, b) Bending upon UV laser irradiation for $2 \mathrm{~s}$. (c) High-frequency (500 Hz) bending by pulsed irradiation ( $1 \mathrm{~ms}$ on/1 $\mathrm{ms}$ off) of the UV laser. 


\section{Two-step bending of the thick $1 \alpha$ crystal by the combination of photoisomerization and the}

photothermal effect

a

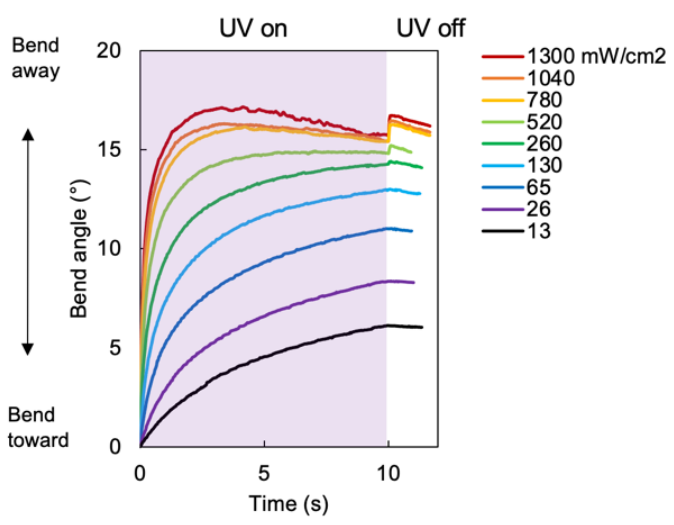

C

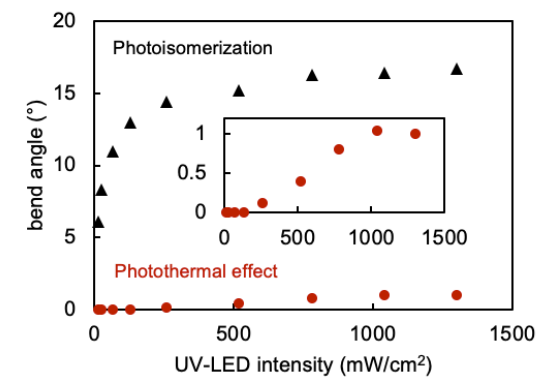

e

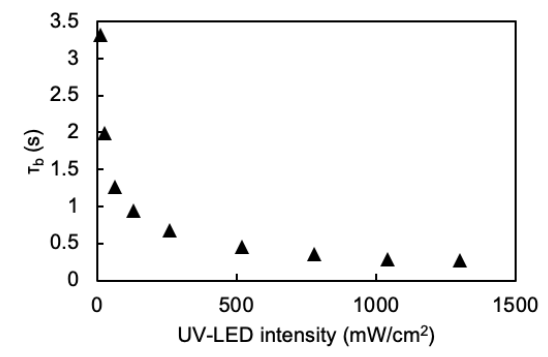

b

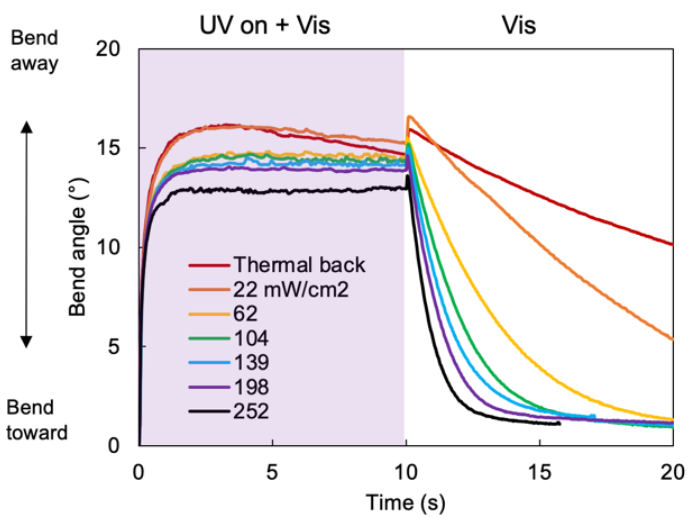

d

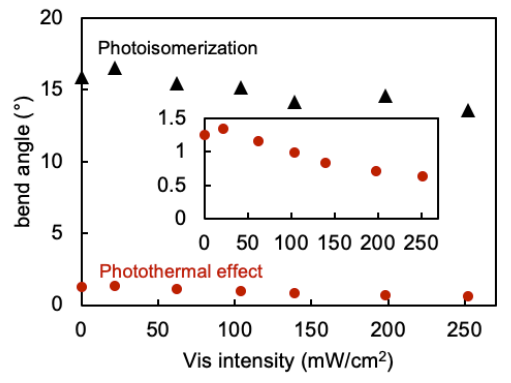

f

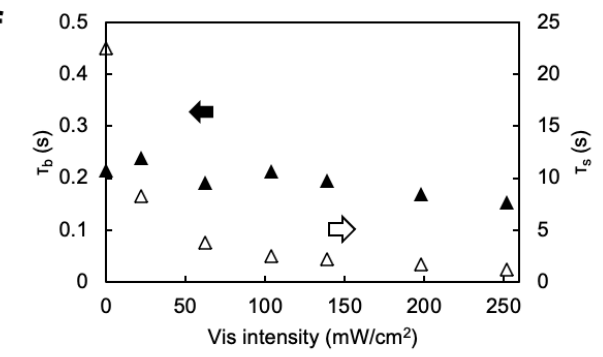

Figure S18. Two-step bending of a slightly thick $1 \alpha$ crystal $\left(1270 \times 49.7 \times 22.4 \mu \mathrm{m}^{3}\right.$, the same crystal in Figure 5 and Figure S10c) upon UV-LED (365 nm) irradiation for 10 s. (a, b) Time dependence of the bend angle (a) with different UV-LED intensity (13-1300 $\mathrm{mW} \mathrm{cm}^{-2}$ ) and (b) upon UV-LED irradiation $\left(1300 \mathrm{~mW} \mathrm{~cm}^{-2}\right)$ under continuous visible light $(520 \mathrm{~nm})$ exposure with different intensity $\left(0-252 \mathrm{~mW} \mathrm{~cm}^{-2}\right)$. (c, d) Intensity dependence of the bend angle and (e, f) time constants for bending (black solid triangles) and straightening (black open triangles) by photoisomerization. 

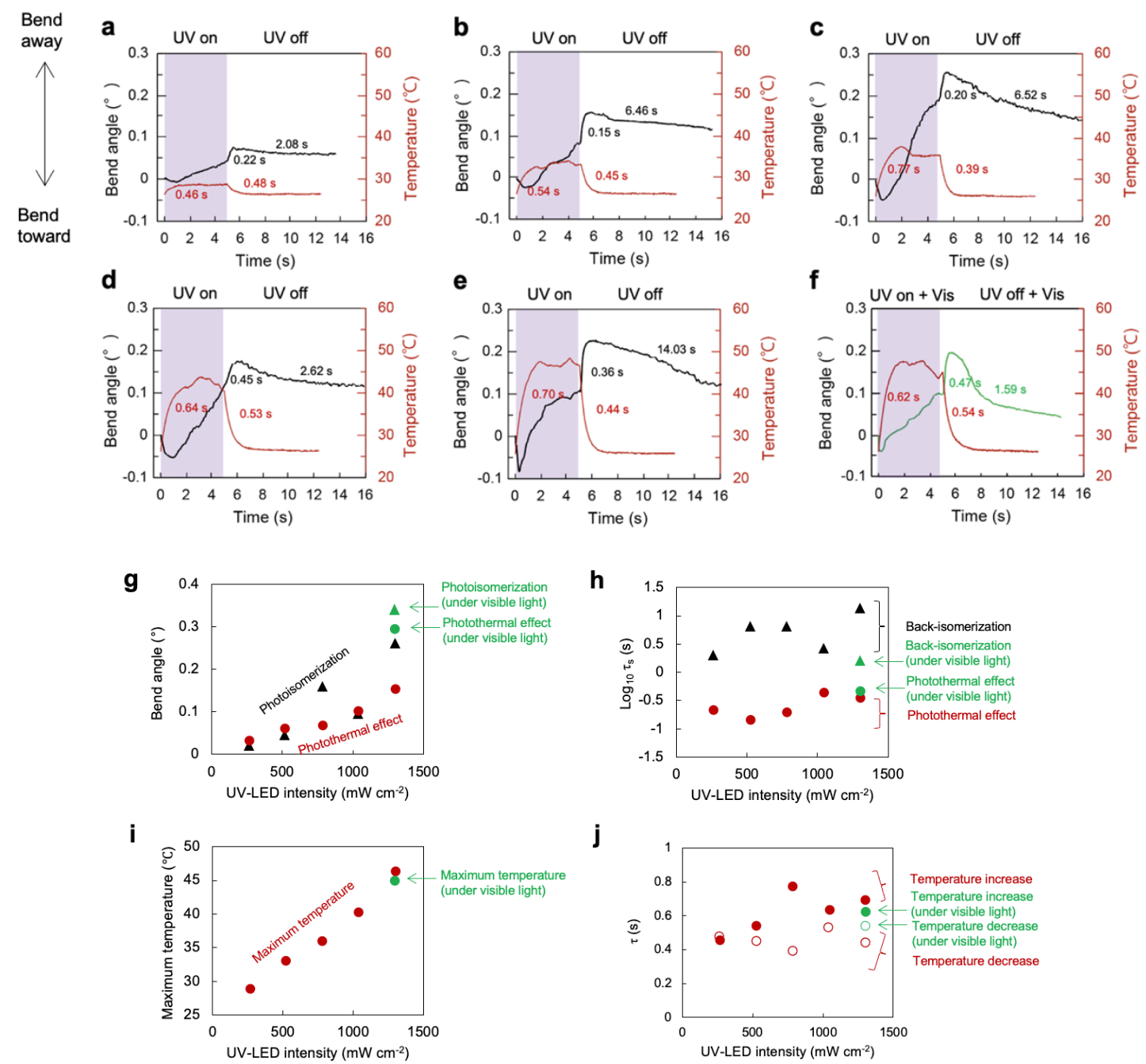

Figure S19. Two-step bending of a thick $1 \alpha$ crystal $\left(2920 \times 451 \times 136 \mu \mathrm{m}^{3}\right.$, the same crystal in Figure 7 and Figure S10d) upon UV-LED $(365 \mathrm{~nm})$ irradiation for $5 \mathrm{~s}$. (a-f) Time dependence of the bend angle (black line) and top surface temperature (red line) with an intensity of (a) 260, (b) 520, (c) 780, (d) 1040 , (e) $1300 \mathrm{~mW} \mathrm{~cm}^{-2}$, and (f) $1300 \mathrm{~mW} \mathrm{~cm}^{-2}$ under continuous visible light (520 nm, $251 \mathrm{~mW}$ $\mathrm{cm}^{-2}$ ) exposure. The numbers in the graphs indicate time constants. (g-j) UV-LED intensity dependence of (g) the maximum bend angle, (h) time constants for bending and straightening, (i) maximum temperature, and (j) time constants for temperature increase and decrease. 
Continued explanation for Figure S19:

The contributions of photoisomerization and the photothermal effect were separated by fitting time dependence of the bend angle after turning off the UV light $(t>5 \mathrm{~s})$ by a biexponential equation; the fast component was regarded as the contribution of the photothermal effect and the slow component as that of photoisomerization. Note that time dependence of the bend angle under UV light irradiation $(0<\mathrm{t}<5 \mathrm{~s})$ was not able to be fitted by a biexponential equation probably due to the close time constants for photoisomerization and the photothermal effect.

a

\begin{tabular}{llll}
\hline & $\begin{array}{l}0{ }^{\circ} \mathrm{C} \\
(\mathrm{n}=6) \\
\text { Average } \pm \\
\text { Standard error }\end{array}$ & $\begin{array}{l}20{ }^{\circ} \mathrm{C} \\
(\mathrm{n}=6)\end{array}$ & $\begin{array}{l}40{ }^{\circ} \mathrm{C} \\
(\mathrm{n}=6)\end{array}$ \\
& $\begin{array}{l}\text { Average } \pm \\
\text { Standard error }\end{array}$ & $\begin{array}{l}\text { Average } \pm \\
\text { Standard error }\end{array}$ \\
\hline Formula & $\mathrm{C}_{22} \mathrm{~N}_{26} \mathrm{NOF}$ & $\mathrm{C}_{22} \mathrm{~N}_{26} \mathrm{NOF}$ & $\mathrm{C}_{22} \mathrm{~N}_{26} \mathrm{NOF}$ \\
Size $\left(\mathrm{mm}^{3}\right)$ & $0.40 \times 0.15 \times 0.10$ & $0.40 \times 0.15 \times 0.10$ & $0.40 \times 0.15 \times 0.10$ \\
$a(\AA)$ & $6.5352 \pm 0.0007$ & $6.5315 \pm 0.0007$ & $6.5283 \pm 0.0005$ \\
$b(\AA)$ & $10.6212 \pm 0.0010$ & $10.6155 \pm 0.0012$ & $10.6173 \pm 0.0010$ \\
$c(\AA)$ & $14.6033 \pm 0.0018$ & $14.6597 \pm 0.0015$ & $14.7245 \pm 0.0024$ \\
$\alpha\left({ }^{\circ}\right)$ & $80.1083 \pm 0.0156$ & $80.1583 \pm 0.0125$ & $80.1583 \pm 0.0543$ \\
$\beta\left({ }^{\circ}\right)$ & $81.755 \pm 0.0173$ & $81.8783 \pm 0.0085$ & $81.945 \pm 0.008$ \\
$y\left(^{\circ}\right)$ & $75.18 \pm 0.0213$ & $75.2367 \pm 0.0184$ & $75.28 \pm 0.008$ \\
\hline
\end{tabular}

b

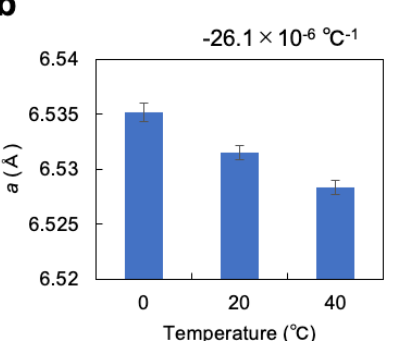

C

d
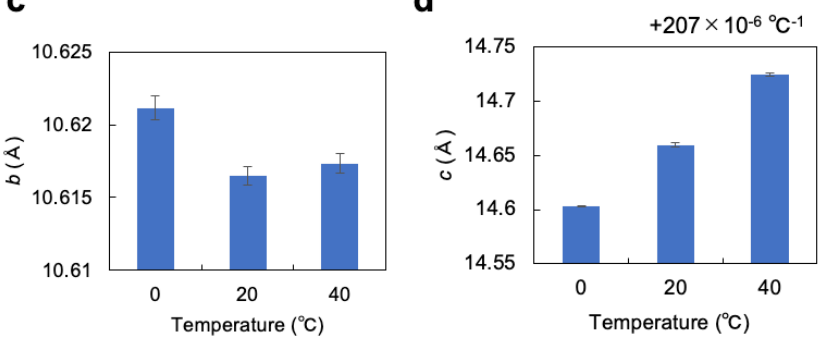

e

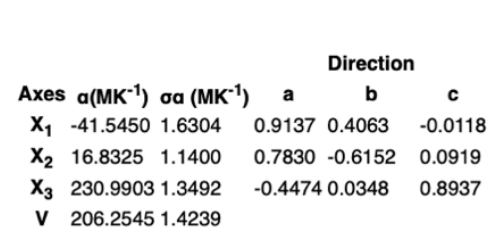

f

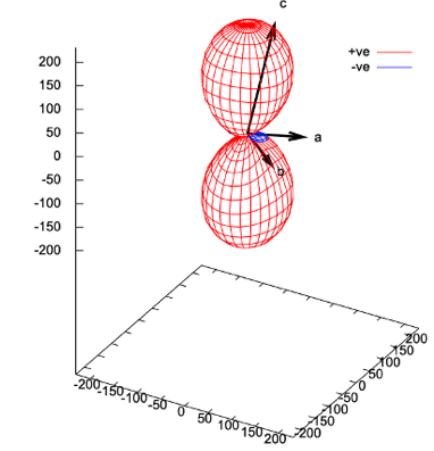

Figure S20. (a) Unit cell parameters of a $1 \alpha$ crystal at 0,20 , and $40^{\circ} \mathrm{C}$. (b-d) Change in length of (b) $a$-, (c) $b$-, and (d) $c$-axes. The numbers in the upper right corner of the graphs indicate the coefficient of thermal expansion. (e) The principal components of the expansivity tensor. $\boldsymbol{a}$ represents the coefficient of thermal expansion $\left(\times 10^{-6}\right)$. (f) The expansivity indicatrix for $1 \alpha$ calculated by using the software, PASCal, ${ }^{2}$ demonstrating that upon heating the $1 \alpha$ crystal expands to the direction of $c$-axis, while contracts along the $a$-axis. 


\section{Bending of the $1 \beta$ polycrystal by the photothermal effect}

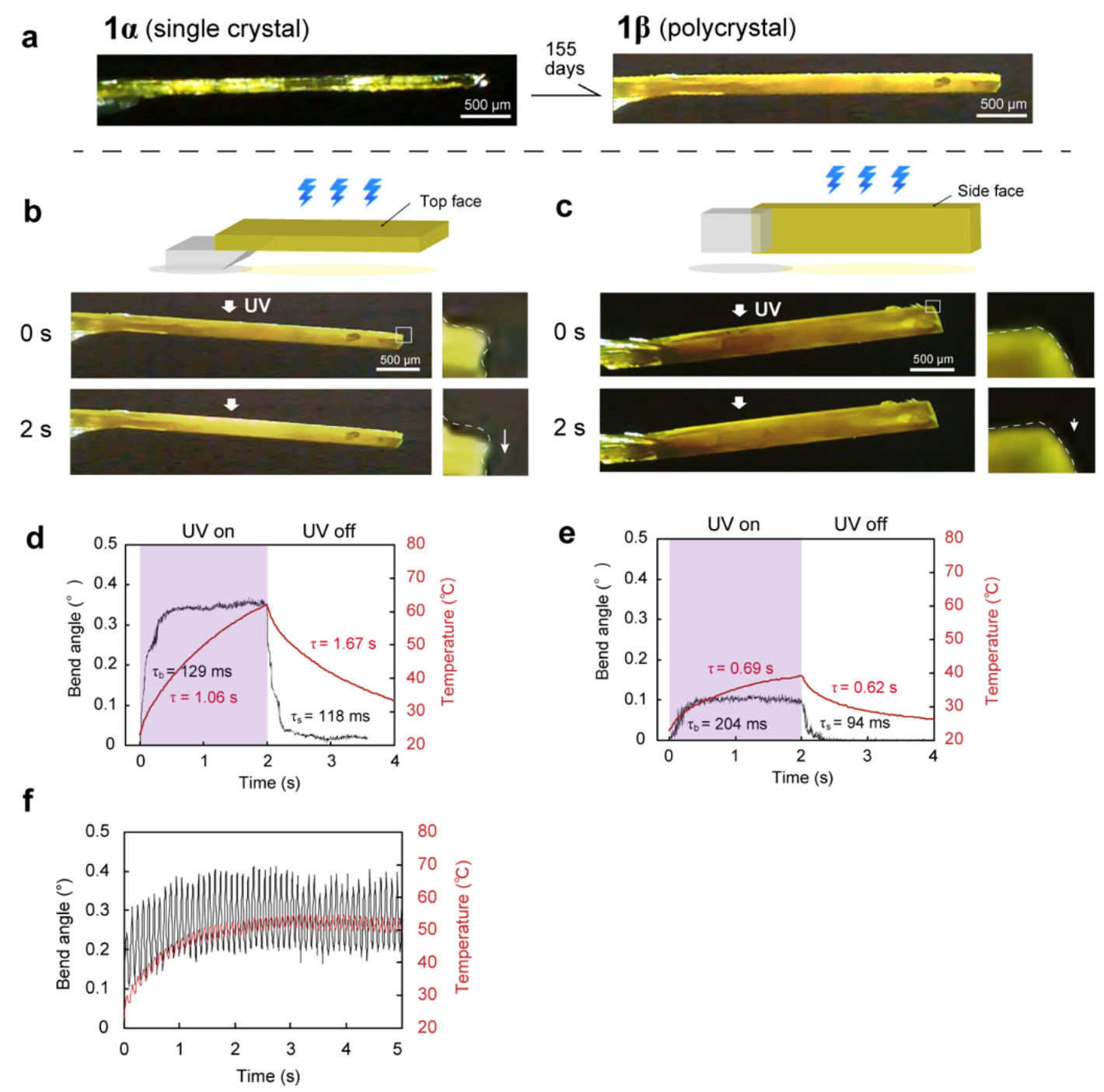

Figure S21. Photomechanical behavior of a $\mathbf{1 \beta}$ polycrystal. (a) A thick $\mathbf{1} \boldsymbol{\alpha}$ crystal $(2920 \times 451 \times 136$ $\mu \mathrm{m}^{3}$, the same crystal in Figure 7 and Figure S10d) transformed to the polycrystalline $\boldsymbol{\beta}$ form in several days at room temperature. The following experiments were conducted 155 days after recrystallization of the $1 \alpha$ crystal. (b-e) Bending away motion by the photothermal effect upon UV-LED (365 nm, $1300 \mathrm{~mW} \mathrm{~cm}^{-2}$ ) irradiation for $2 \mathrm{~s}(\mathrm{~b}, \mathrm{~d})$ to the top face and (c, e) to the side face (Movie S5). (d, e) Time dependence of the bend angle and maximum temperature of the irradiated surface. (f) $5 \mathrm{~Hz}$ bending upon pulsed UV laser irradiation $(0.1 \mathrm{~s}$ on/ $0.1 \mathrm{~s}$ off $)$ to the top face. 


\title{
8. Experimental section
}

X-ray Crystallographic Analyses. Single-crystal X-ray diffraction data of enol-1 were collected using a R-AXIS RAPID-F instrument (Rigaku Corp., Tokyo, Japan) with monochromatic Mo Ka radiation ( $\lambda=0.71075 \AA$ ). The temperature of the sample was regulated using a $\mathrm{N}_{2}$ gas flow cryostat and calibrated with a thermocouple. Unit cell parameters before and under UV laser irradiation (375 $\mathrm{nm} ; 960 \mathrm{~mW} \mathrm{~cm}^{-2}$; FOLS-03, Sawaki Kobo, Shizuoka, Japan) were also measured using this diffractometer. The structures were resolved by direct methods (SHELXT) ${ }^{3}$ and refined on $F_{2}$ using full-matrix least-squares techniques (SHELXL). ${ }^{4}$ Calculations were performed with the Rigaku CrystalStructure software package (Rigaku) ${ }^{5}$ and a graphical interface, Olex2. ${ }^{6}$

\begin{abstract}
Absorption Spectra. The ultraviolet-visible (UV-vis) absorption spectra of a thin plate-like crystal were measured using a conventional optical microscope equipped with an optical fiber connected to a spectrometer (Exemplar Plus LS, B\&W Tek, Inc., Newark, DE, USA), a measurement light (a 68 W xenon lamp, X 100/110V 68W E17/L, Kawakami Kogyo, Niigata, Japan), and a temperaturecontroller stage (LMT-600S, Collet Kogyo Co., Ltd., Tokyo, Japan). The transmitted light intensity through the sample was measured over the wavelength range of 360-800 nm at 1-nm resolution, with an acquisition time of $30 \mathrm{~ms}$. To clarify photoisomerization properties, the sample was irradiated with a UV laser (375 nm; $90 \mathrm{mWcm}^{-2}$; FOLS-03, Sawaki Kobo). After the spectral change became saturated, the UV light was turned off; the crystal was then kept on the stage or exposed to visible light illumination (520 nm; $62 \mathrm{~mW} \mathrm{~cm}^{-2}$; FOLS-02, Sawaki Kobo).
\end{abstract}

Transient Absorption Spectra. Transient absorption spectra on a microscope were measured by means of femtosecond pump-probe experiments (see Figure S8). The light source was an amplified mode-locked Ti:sapphire laser (Solistice, Spectra-Physics, Milpitas, CA, USA), and the excitation wavelength was $400 \mathrm{~nm}$. A transient absorption spectrum was probed using delayed pulses of a femtosecond white-light continuum generated by focusing the signal light (at $1.3 \mu \mathrm{m}$ ) generated by an optical parametric amplifier (TOPAS, Light Conversion Ltd., Vilnius, Lithuania) onto a $\mathrm{CaF}_{2}$ plate. The probe pulses were detected by a complementary metal oxide semiconductor detector (PMA-20, Hamamatsu Photonics, Shizuoka, Japan). The sample stage was moved periodically with a speed of $10 \mu \mathrm{m} \mathrm{s}^{-1}$ so that the pulse beam scan over a single crystal minimizing an effect of accumulation of photoproducts. The temporal resolution was approximately $200 \mathrm{fs}$.

Fluorescence Quantum Yield. The fluorescence quantum yield of the $1 \beta$ crystal was determined with an absolute photoluminescence quantum yield spectrometer (Quantaurus-QY Plus C13532-21, Hamamatsu Photonics) by measuring the photoluminescence of powder $1 \beta$ crystal excited by $400-\mathrm{nm}$ radiation from a $150-\mathrm{W}$ xenon lamp. 


\section{List of movies}

Movie S1: bending of the thin plate-like $1 \alpha$ microcrystal $\left(167 \times 15.0 \times 0.5 \mu \mathrm{m}^{3}\right)$ with a twist by photoisomerization upon UV-LED $\left(365 \mathrm{~nm}, 180 \mathrm{~mW} \mathrm{~cm}^{-2}\right)$ irradiation from the right for $3.4 \mathrm{~s}$ (real time) (MP4)

Movie S2: bending and surface temperature change of the large needle-like $1 \beta$ crystal $(5600 \times 65.0 \times$ $\left.34.0 \mathrm{~mm}^{3}\right)$ by the photothermal effect upon UV laser $\left(375 \mathrm{~nm}, 960 \mathrm{~mW} \mathrm{~cm}{ }^{-2}\right)$ irradiation from the top for $2.4 \mathrm{~s}$ (real time) (MP4)

Movie S3: $500 \mathrm{~Hz}$ high-frequency bending of the large needle-like $\mathbf{1 \beta}$ crystal $(5600 \times 65.0 \times 34.0$ $\mu \mathrm{m}^{3}$ ) by pulsed UV laser exposure ( $375 \mathrm{~nm}, 960 \mathrm{~mW} \mathrm{~cm}{ }^{-2}, 1 \mathrm{~ms}$ on/ $1 \mathrm{~ms}$ off) (Slow motion $\times 0.04$ ) (MP4)

Movie S4: two-step bending and surface temperature change of the thick plate-like $1 \boldsymbol{\alpha}$ crystal (2920 $\left.\times 451 \times 136 \mu \mathrm{m}^{3}\right)$ by photoisomerization and the photothermal effect upon UV-LED $(365 \mathrm{~nm}, 1300$ $\mathrm{mW} \mathrm{cm}{ }^{-2}$ ) irradiation from the top for $5.0 \mathrm{~s}$ (MP4)

Movie S5: bending and surface temperature change of the $\mathbf{1 \beta}$ polycrystal $\left(2920 \times 451 \times 136 \mu \mathrm{m}^{3}\right)$ by the photothermal effect (real time) (MP4) 


\section{References}

(1) Turner, M. J.; Thomas, S. P.; Shi, M. W.; Jayatilaka, D.; Spackman, M. A. Energy frameworks: insights into interaction anisotropy and the mechanical properties of molecular crystals. Chem. Commun. 2015, 51, 3735-3738.

(2) Cliffe, M. J.; Goodwin, A. L. PASCal: a principal axis strain calculator for thermal expansion and compressibility determination. J. Appl. Cryst. 2012, 45, 1321-1329.

(3) Sheldrick, G. M. SHELXT - Integrated space-group and crystal-structure determination. Acta Crystallogr., Sect. A: Found. Adv. 2015, A71, 3-8.

(4) Sheldrick, G. M. Crystal structure refinement with SHELXL. Acta Crystallogr., Sect. C: Struct. Chem. 2015, C71, 3-8.

(5) CrystalStructure, ver. 4.2.2.; Rigaku Corporation: Tokyo, Japan, 2016.

(6) Dolomanov, O. V.; Bourhis, L. J.; Gildea, R. J.; Howard, J. A. K.; Puschmann, H. OLEX2: a complete structure solution, refinement and analysis program. J. Appl. Cryst. 2009, 42, 339-341. 